\title{
(E) \\ Corrosion Product Formation Monitored Using the Feedback Mode of Scanning Electrochemical Microscopy with Carbon Microelectrodes
}

\author{
Philippe Dauphin-Ducharme, ${ }^{a}$ Christian Kuss, ${ }^{\text {a,* }}$ David Rossouw, ${ }^{b}$ Nicholas A. Payne, ${ }^{\text {a, }}$

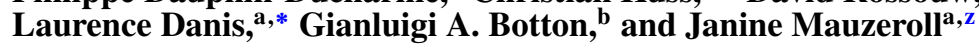 \\ ${ }^{a}$ Laboratory for Electrochemical Reactive Imaging and Detection of Biological Systems, McGill University, Montreal, \\ QC H3A OB8, Canada \\ ${ }^{b}$ Department of Materials Science and Engineering, Brockhouse Institute for Materials Research and Canadian Centre \\ for Electron Microscopy, McMaster University, Hamilton, Ontario L8S 4M1, Canada
}

\begin{abstract}
When studying magnesium alloy corrosion, the quantitative analysis of probe approach curves acquired in the feedback mode of scanning electrochemical microscopy is particularly challenging. The oxidation current of the ferrocenemethanol mediator recorded at conventional Pt microelectrodes is systematically plagued by parasitic faradaic contribution from the oxidation hydrogen. Herein we demonstrate the use of carbon microelectrodes to remove this unwanted faradaic contribution, allowing for in situ time lapse monitoring of the corrosion product layer growth. Applying a one-dimensional diffusion approximation, the extracted rate constants obtained by scanning electrochemical microscopy probe approach curves could be correlated to the corrosion product film thickness and porosity obtained by transmission electron microscopy.

(C) The Author(s) 2015. Published by ECS. This is an open access article distributed under the terms of the Creative Commons Attribution 4.0 License (CC BY, http://creativecommons.org/licenses/by/4.0/), which permits unrestricted reuse of the work in any medium, provided the original work is properly cited. [DOI: 10.1149/2.0701512jes] All rights reserved.
\end{abstract}

Manuscript submitted July 30, 2015; revised manuscript received September 4, 2015. Published September 18, 2015.

Scanning probe techniques have proven very successful in assessing corrosion in situ. These techniques can measure currents and/or potentials with high spatial resolution, to grasp the complexity of corrosion and de-convolute electrochemical fluxes, which is mandatory in order to find initiation sites or estimate the material's resistance to corrosion.

Scanning electrochemical microscopy (SECM) is a scanning probe technique that maps the heterogeneous electrochemical activity of an immersed sample using a microelectrode (ME). ${ }^{1,2}$ SECM can decouple the surface reactivity from its topography and encompasses a wide variety of modes. ${ }^{1,2}$ In corrosion science, the generation-collection, feedback and potentiometric modes were used to characterize ${ }^{3}$ or initiate $^{4}$ pitting corrosion, probe a precise ion of interest ${ }^{5-7}$, and quantify surface reactivity of heterogeneous materials ${ }^{8}$. The feedback mode $^{9-12}$, which relies on the addition of a redox mediator in the corroding solution ${ }^{13,14}$ and substrate-generation/tip-collection ${ }^{9,15}$ mode, through the directed detection of evolved $\mathrm{H}_{2}$ evolution ${ }^{16,17}$ have been used to quantify the localized heterogeneous reactivity of corroding $\mathrm{Mg}$ alloys.

During the corrosion of $\mathrm{Mg}$ and its alloys ${ }^{9}$, the main corrosion reactions of $\mathrm{Mg}$ are: ${ }^{18}$

$$
\begin{gathered}
\mathrm{Mg}_{(\mathrm{s})} \rightarrow \mathrm{Mg}^{2+}{ }_{(\mathrm{aq})}+2 \mathrm{e}^{-} \\
2 \mathrm{H}_{2} \mathrm{O}_{(\mathrm{aq})}+2 \mathrm{e}^{-} \stackrel{\leftrightarrows}{\rightarrow} 2 \mathrm{OH}^{-}{ }_{(\mathrm{aq})}+\mathrm{H}_{2(\mathrm{aq}+\mathrm{g})} \\
\mathrm{Mg}_{(\mathrm{aq})}^{2+}+2 \mathrm{OH}_{(\mathrm{aq})}^{-} \stackrel{\leftarrow}{\rightarrow} \mathrm{Mg}(\mathrm{OH})_{2(\mathrm{~s})}
\end{gathered}
$$

The Mg matrix is oxidized and dissolves through the generation of $\mathrm{Mg}^{2+}$ (Eq. 1), while the main cathodic reaction, water reduction, generates an increase in $\mathrm{pH}$ as well as dissolved and gaseous $\mathrm{H}_{2}$ (Eq. 2). Finally, with increasing immersion time, corrosion products precipitate (Eq. 3) when reaching the solubility limit of $\mathrm{Mg}(\mathrm{OH})_{2}\left(K_{\text {sp. }}\right.$, $\left.\mathrm{Mg}(\mathrm{OH})_{2}=5.61 \times 10^{-12}\right)^{19}$.

In feedback mode, the choice of usable redox mediators in the magnesium corrosion system is limited by its low corrosion potential $\left(\mathrm{E}^{\mathrm{o}}<-1.5 \mathrm{~V} \text { vs. SCE}\right)^{20}$ and the high $\mathrm{pHs}$ obtained as corrosion progresses. ${ }^{21}$ Additionally, the oxidation current of common iron based redox mediators, such as ferrocenemethanol $(\mathrm{FcMeOH})$,

*Electrochemical Society Student Member.

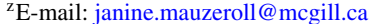

recorded at conventional $\mathrm{Pt}$ microelectrodes (biased at $\sim 350 \mathrm{mV}$ vs. $\left.\mathrm{Ag} \mid \mathrm{AgCl}\left(\mathrm{FcMeOH} \rightarrow \mathrm{FcMeOH}^{+}+\mathrm{e}^{-}\right)\right)$is systematically plagued by parasitic faradaic contributions from the collection of $\mathrm{H}_{2}(\geq-100$ $\mathrm{mV}$ vs. $\mathrm{Ag} \mid \mathrm{AgCl}$, and $\mathrm{pH}$ dependent $)^{15}$, Figure 1 . Since the $\mathrm{ME}$ current depends linearly on the diffusion coefficient, ${ }^{11}$ which is about $10 \times$ higher for $\mathrm{H}_{2}$ than for $\mathrm{FcMeOH}$ in aqueous media $\left(5 \times 10^{-5}\right.$ $\mathrm{cm}^{2} \mathrm{~s}^{-116}$ for $\mathrm{H}_{2}$ vs. $7.8 \times 10^{-6} \mathrm{~cm}^{2} \mathrm{~s}^{-122}$ for $\left.\mathrm{FcMeOH}\right)$, the ME current will in majority be due to $\mathrm{H}_{2}$ oxidation, making changes in the $\mathrm{FcMeOH}$ oxidation current difficult to assess.

There have been five reports presenting strategies to mitigate the simultaneous detection of $\mathrm{H}_{2}$ and the feedback current during $\mathrm{Mg}$ alloy corrosion. In a study targeting the use of $\mathrm{Mg}$ alloys as biodegradable implants, Jamali et al. employed an aqueous buffer to characterize the corrosion using $\mathrm{FcMeOH}$ and control the rate of $\mathrm{H}_{2}$ evolution. ${ }^{9}$ Our group recently reported the use of non-aqueous media (ethylene glycol) in combination with $\mathrm{FcMeOH}$ to investigate $\mathrm{Mg}$ alloy surface reactivity for automotive applications, limiting $\mathrm{H}_{2}$ evolution severely. ${ }^{23}$ Moreover, the use of arsenic as a cathodic poison ${ }^{24}$ or a decreased concentration of $\mathrm{NaCl}$ electrolyte solution ${ }^{9,15}$ are also avenues that have succeeded in decreasing $\mathrm{H}_{2}$ evolution.

Herein, we propose a simple method to use SECM feedback mode to study $\mathrm{Mg}$ alloy corrosion in situ. Using a carbon ME (C-ME), which is directly amenable to any electrolyte solution, the faradaic current contribution from $\mathrm{H}_{2}$ can be avoided. C-MEs have been used to probe corrosion of oxide films as they offer a stable electrochemical behavior and an extended window at lower potentials in comparison to $\mathrm{Pt}$ and $\mathrm{Au}$ MEs. ${ }^{25-27} \mathrm{C}$-MEs are unreactive towards $\mathrm{H}_{2}$, allowing in situ time lapse monitoring of the corrosion product layer growth of AM50 Mg alloys using conventional feedback mode SECM in $\mathrm{FcMeOH}$.

\section{Experimental}

Sample preparation. $-1 \mathrm{~cm} \times 1 \mathrm{~cm} \times 0.7 \mathrm{~cm}$ and $0.5 \mathrm{~cm} \times 0.5$ $\mathrm{cm} \times 0.7 \mathrm{~cm}$ samples were machined from sand cast and graphite cast AM50 Mg alloy rods respectively, received from Generals Motors Canada (see ICP-MS results for elemental composition elsewhere ${ }^{5}$ ). Graphite and sand cast AM50 Mg alloys were selected due to their exceptional castability and good corrosion resistance directly amenable for automotive applications. ${ }^{28}$ Cold mounting epoxy (Epofix - Struers) is used to fix the samples followed by a SiC paper $(800,1200,2400$ grit) coarse polishing step. The surface is then brought to a mirror finish by first performing a fine polishing step using a $3 \mu \mathrm{m}$ diamond 


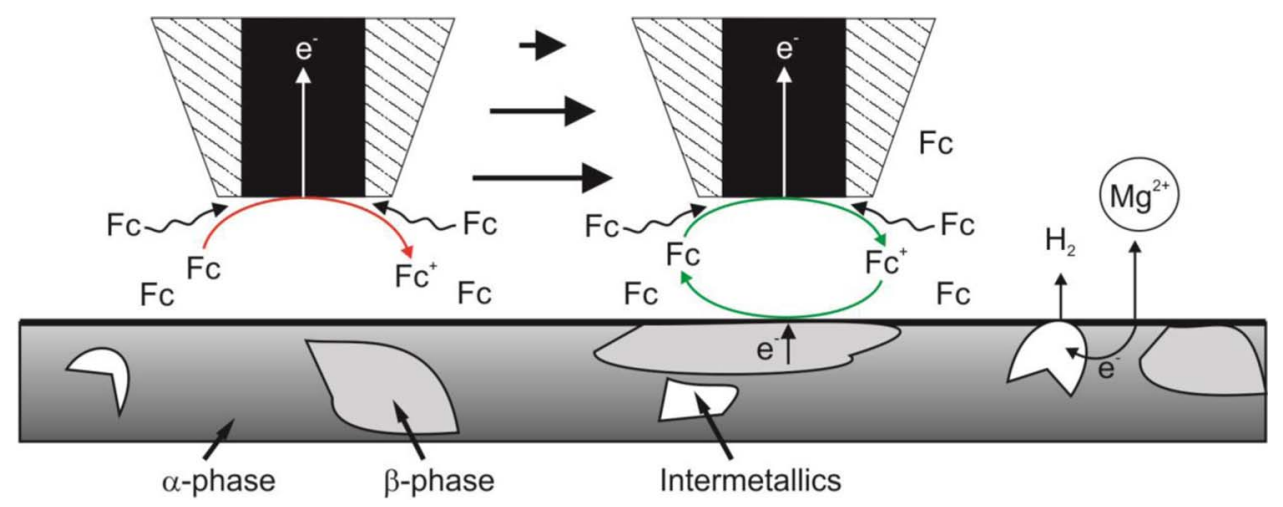

Figure 1. Schematic representation of microgalvanic corrosion of $\mathrm{Mg}$ alloy and surface reactivity monitoring using the feedback mode (negative (red) and positive (green) feedback) of SECM using a redox mediator $(\mathrm{Fc})$. The ME is biased at $\sim 350 \mathrm{mV}$ to oxidize the mediator, which also leads to $\mathrm{H}_{2}$ collection.

paste (Dia 3, Struers) with a Struers MD Dur cloth followed by a mixture of ethylene glycol and $0.04 \mu \mathrm{m}$ colloidal silica (1:1) on a Struers MD Chem cloth. ${ }^{29}$ Sonication of the polished samples in anhydrous ethanol for $2 \mathrm{~min}$ was performed to remove aggregates of silica and then dried under an Ar stream.

Instrumentation.- Following immersion, samples were imaged at $300 \times$ magnification across an area of $2 \mathrm{~mm} \times 2 \mathrm{~mm}$ using a Hitachi SU3500 Variable Pressure-scanning electron microscope (SEM) equipped with an XEDS (Oxford, Inca, Silicon drift detector). The micrographs were then stitched together using Corel Draw X5 into a grid yielding the final image, as presented elsewhere. ${ }^{17}$

An ElProScan 3 system (HEKA, Germany; bipotentiostat model PG340) SECM was used to image Mg alloy heterogeneous reactivity with a $11 \mu \mathrm{m}$ carbon fiber ME, fabricated following literature. ${ }^{30}$ The C-ME electrochemical behavior was compared to a $10 \mu \mathrm{m}$ Pt ME fabricated with the same procedure. ${ }^{30}$ A $1 \mathrm{mM} \mathrm{FcMeOH}$ (Acros Organic, New Jersey, USA) with 0.016 wt. $\%(2.7 \mathrm{mM}) \mathrm{NaCl}$ (ACP, Montreal, Quebec) aqueous solution (Millipore Milli-Q water $18.2 \mathrm{M} \Omega-\mathrm{cm}$ ) was used to probe surface reactivity. The C-ME was positioned at 5 $\mu \mathrm{m}$ above the $\mathrm{Mg}$ alloy sample using a feedback approach curve and rastered across the sample at $2 \mu \mathrm{m} / \mathrm{s}$ while polarizing the ME tip at $+350 \mathrm{mV}$ vs. $\mathrm{Ag} \mid \mathrm{AgCl}$. Line scans toward epoxy edges with the same parameters allowed the determination of ME position to overlay the electron micrograph. $\mathrm{Ag} \mid \mathrm{AgCl}$ reference (prepared following literature procedure ${ }^{31}$ using a $1.0 \mathrm{~mm}$ diameter, annealed $99.99 \% \mathrm{Ag}$ wire, Goodfellow) and Pt counter electrodes were employed for the SECM measurements. The SECM experiment was halted by rinsing the $\mathrm{Mg}$ alloy thoroughly with anhydrous ethanol.

Transmission electron microscopy (TEM) analyses were performed by using a focused ion beam (FIB-Zeiss NVision 40, equipped with an XEDS- Oxford, Inca, Silicon drift detector) from locations on corroded surfaces. Microscopic characterization of the focused ion beam (FIB) samples was performed on an FEI Titan 80-300 (scanning) transmission electron microscope, (S)TEM, equipped with a X-Ray energy dispersive spectroscopy (XEDS- Oxford, Inca, Si(Li) detector) and an electron energy loss spectroscopy (EELS) (Gatan Quantum). Further details of the electron microscopy and spectroscopic characterization can be found elsewhere. ${ }^{32}$

Numerical simulations of SECM feedback approach curves over the corrosion product film were performed using the finite element method (FEM) in COMSOL Multiphysics 5.0. Details of the simulation parameters are given in the Supporting Information. Eq. 4 was established independently of the model, based on Fick's first law of diffusion.

\section{Results and Discussion}

Avoiding $\mathrm{H}_{2}$ collection with C-MEs.- Figure 2A presents two cyclic voltammograms of a $10 \mu \mathrm{m}$ Pt ME recorded without (full line) substrate and above a sand cast AM50 Mg alloy (dash line) immersed in a $1 \mathrm{mM} \mathrm{FcMeOH}$ solution. In the absence of the $\mathrm{Mg}$ alloy, a steadystate anodic current of $1.5 \mathrm{nA}$ is measured in the $\mathrm{FcMeOH}$ solution. Upon $\mathrm{Mg}$ alloy immersion in the $\mathrm{FcMeOH}$ solution, a tenfold increase in anodic current is recorded at the Pt ME (dashed line in Figure 2A,

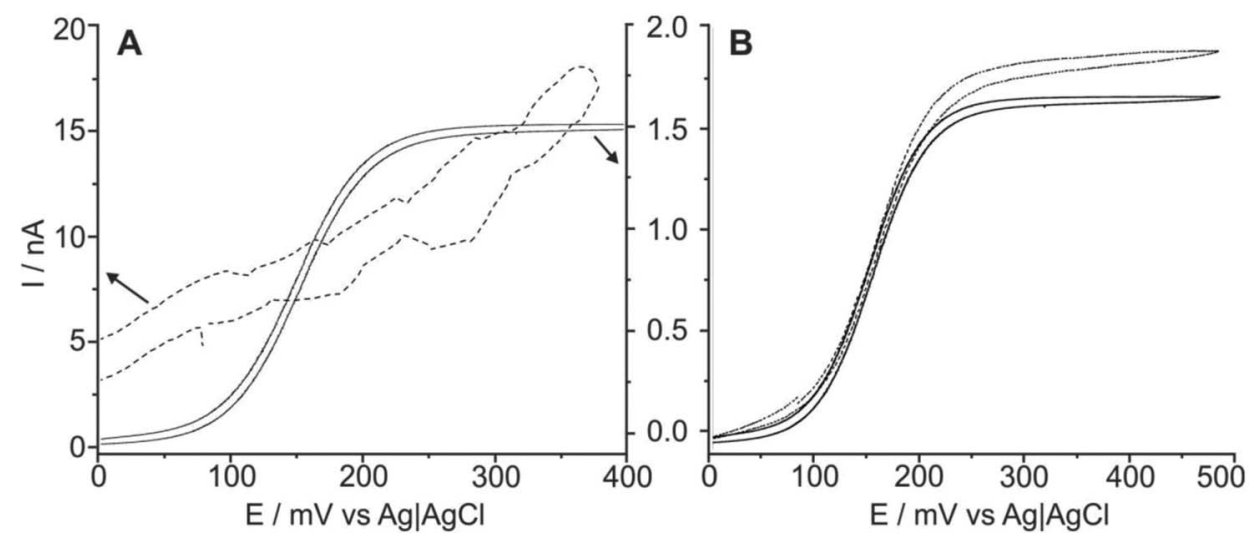

Figure 2. A) Cyclic voltammograms of a $10 \mu \mathrm{m}$ Pt ME in a $1 \mathrm{mM} \mathrm{FcMeOH}$ solution with (dash curve) and without (full line curve) the Mg alloy immersed; B) Cyclic voltammograms of a $11 \mu \mathrm{m} \mathrm{C-ME} \mathrm{in} \mathrm{a} 1 \mathrm{mM} \mathrm{FcMeOH}$ solution in presence (dash curve) and without (full line curve) the $\mathrm{Mg}$ alloy immersed. A Pt counter electrode was used. 
with a tip-to-substrate distance $>1 \mathrm{~mm}$ ). This increase is associated with the oxidation of dissolved $\mathrm{H}_{2}$ evolved from the $\mathrm{Mg}$ alloy surface and overshadows the feedback FcMeOH signal. The use of C-MEs overcomes this issue and is not affected by faradaic contribution of dissolved $\mathrm{H}_{2}$, Figure $2 \mathrm{~B}$. A cyclic voltammogram of a $1 \mathrm{mM} \mathrm{FcMeOH}$ solution recorded using a $11 \mu \mathrm{m} \mathrm{C}-\mathrm{ME}$ shows a steady-state response of $1.7 \mathrm{nA}$ (full line curve). Upon immersion of the $\mathrm{Mg}$ alloy in the redox mediator solution (dash line curve), the steady-state response of the C-ME slightly increases $\sim 1.8-1.9 \mathrm{nA}$, which can be related to the reduction of residual $\mathrm{FcMeOH}^{+}$by the $\mathrm{Mg}$ alloy. This increases the concentration of $\mathrm{FcMeOH}$, and thus the steady-state current. C-MEs are thus well suited to avoid the faradaic contribution of dissolved $\mathrm{H}_{2}$ evolved during the corrosion of $\mathrm{Mg}$ alloys and isolate the feedback signal. This can be explained since carbon is chemically inert avoiding $\mathrm{H}_{2}$ adsorption, mandatory for subsequent catalytic dissociation, as opposed to $\mathrm{Pt}^{33}$

$\mathrm{FcMeOH}^{+}$stability during the corrosion of $\mathrm{Mg}$ alloys. $-\mathrm{Mg}$ alloys react immediately upon immersion in solution demanding a stable redox mediator when using the feedback mode of SECM. While other electrochemical fluxes $\left(\mathrm{pH}\right.$ and $\mathrm{Mg}^{2+}$ ) have shown not to interact with this redox mediator ${ }^{9}, \mathrm{FcMeOH}^{+}$may be reduced by formed $\mathrm{H}_{2}{ }^{21}$. Its stability in the presence of $\mathrm{H}_{2}$ was evaluated by performing a control experiment in which $\mathrm{FcMeOH}^{+}$is exposed to a saturated solution of $\mathrm{H}_{2}$ in water. The change in $\mathrm{FcMeOH}^{+}$concentration was monitored by UV/Vis spectrophotometry, showing no significant effect of $\mathrm{H}_{2}$ on the $\mathrm{FcMeOH}^{+}$concentration, whereas it is significantly reduced in the presence of small amounts of magnesium metal, Figure S2. Hence, we expect that $\mathrm{FcMeOH}^{+}$will be reduced only at the substrate resulting in a positive feedback loop.

Time-dependent SECM feedback response over Mg alloy.- Having established the feasibility of $\mathrm{FcMeOH}$ feedback studies on $\mathrm{Mg}$ with C-MEs, the time-dependence of the feedback current signal was assessed by performing probe approach curves over a graphite cast AM50 Mg alloy. The four intermediate curves presented in Figure 3 are representative probe approach curves recorded over the $\mathrm{Mg}$ alloy for immersion times of $15 \mathrm{~min}, 1 \mathrm{~h}, 2 \mathrm{~h}$ and $4 \mathrm{~h}$, respectively. Overall, the probe approach curves recorded using the C-ME, display an intermediate behavior to the diffusion limited positive and negative probe approach curves. The results demonstrate that the $\mathrm{Mg}$ alloy surfaces, reported to exhibit an insulating oxide layer ${ }^{10}$, remain active through-

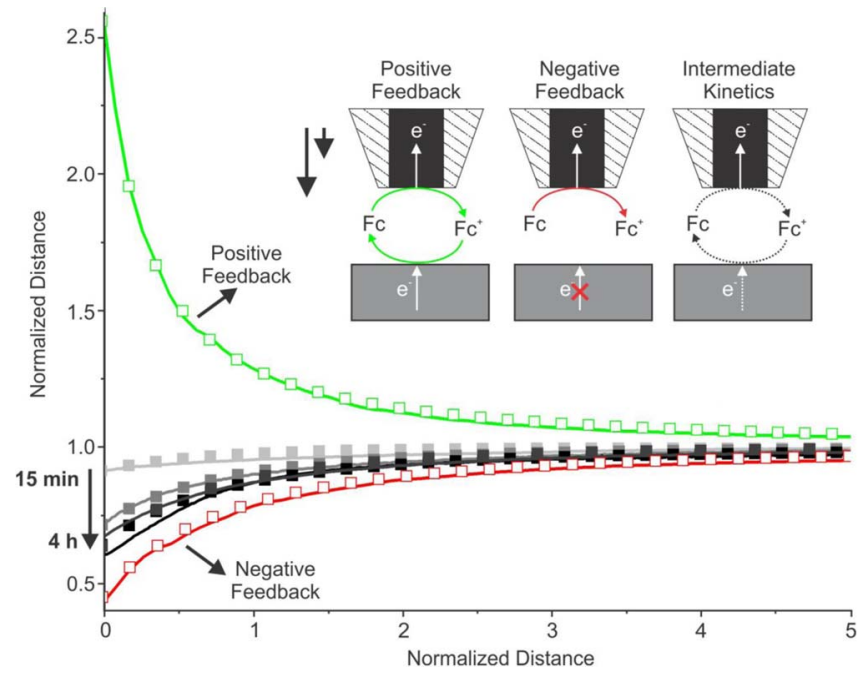

Figure 3. Representative probe approach curves and analytical approximation fits ( $\square / \mathbf{\square}$ ) recorded at $1 \mu \mathrm{m} / \mathrm{s}$ using a C-ME over pure positive (Pt substrate, green curve), negative (Teflon substrate, red curve) feedback controlled substrates and graphite cast $\mathrm{Mg}$ alloy (grayscale curves) for different immersion times $(15 \mathrm{~min}, 1 \mathrm{~h}, 2 \mathrm{~h}$ and $4 \mathrm{~h}$ ). The tip was polarized at $+350 \mathrm{mV}$ vs. $\mathrm{Ag} \mid \mathrm{AgCl}$ to induce oxidation of the mediator. out the corrosion process ${ }^{32}$. Immersion times exceeding $4 \mathrm{~h}$ resulted in superimposable responses to that presented in Figure $3(4 \mathrm{~h})$. The negative feedback behavior is not reached, which indicates that the $\mathrm{FcMeOH}^{+}$can penetrate the corrosion product (mainly $\mathrm{Mg}(\mathrm{OH})_{2}$ ) layer because it remains porous.

Fitting the probe approach curves in Figure 3 to an analytical approximation of kinetically limited feedback behavior, one extracts the apparent heterogeneous rate constant $\left(k^{a}\right)$ of the $\mathrm{Mg}$ alloy surface under the electrode. ${ }^{34} k^{a}$ values for immersion times of $15 \mathrm{~min}, 1 \mathrm{~h}$, $2 \mathrm{~h}$ and $4 \mathrm{~h}$ are respectively $3.5 \times 10^{-3} \mathrm{~cm} \mathrm{~s}^{-1}, 1.4 \times 10^{-3} \mathrm{~cm} \mathrm{~s}^{-1}$, $1.1 \times 10^{-3} \mathrm{~cm} \mathrm{~s}^{-1}$ and $1.0 \times 10^{-3} \mathrm{~cm} \mathrm{~s}^{-1}$.

The time dependence of these apparent rate constants reveals a rapid corrosion and a decrease in surface heterogeneous reactivity with increasing immersion time. This observation is in agreement with a decrease in the evolution of dissolved hydrogen following $1 \mathrm{~h}$ of immersion, according to a previous report. ${ }^{16}$ Moreover, this decrease in the $k$ values could also be correlated to an increase in the corrosion product film thickness, which further hinders the access of the mediator to the active surface.

Microgalvanic corrosion of Mg alloy in SECM feedback mode.Given the observed decrease in $k$ with increasing immersion time, SECM mapping with immersion times $<1-2 \mathrm{~h}$ are required to identify the $\mathrm{Mg}$ microstructure where corrosion is rapidly initiated. The time dependence of the measured feedback current in the first $2 \mathrm{~h}$ is expected to strongly depend on the microgalvanic features of the $\mathrm{Mg}$ alloy, which can be probed using SECM current maps.

In line with an established method, ${ }^{17}$ a sand cast AM50 Mg alloy was imaged by SEM over an area of $2 \times 2 \mathrm{~mm}$, post corrosion, Figure 4A. An area of interest (AOI) is selected (white square on the micrograph), which comprised $\alpha$-phase, $\beta$-phase $\left(\mathrm{Mg}_{17} \mathrm{Al}_{12}\right)$ and Al-Mn intermetallics $\left(\mathrm{Al}_{8} \mathrm{Mn}_{5}\right)$ features (see the higher magnification micrograph in Figure 4B). A C-ME was then positioned $5 \mu \mathrm{m}$ above the sand cast AM50 Mg alloy through a feedback current probe approach curve. Line scans across the surface were then acquired to locate the epoxy edges surrounding the $\mathrm{Mg}$ alloy and later used to cross-correlate the SECM maps to acquired electron microscopy images. Figure 5A presents a feedback current map recorded across the AOI (Figure 4B). This map shows several high current regions ( $>0.86$ normalized current) of $\sim 10-15 \mu \mathrm{m}$ diameter as well as some low current regions $(\sim 0.86$ normalized current $)$ of the same size. Smaller regions $(<10 \mu \mathrm{m})$ where variations in the measured currents are recorded are likely attributed to current spikes as they can not be resolved with the microelectrode used. An overlay of Figure 5A and Figure 4B (inset of Figure 5B) reveals that the higher current regions are co-located with secondary features. XEDS maps of the AOI (see Figure S1), following a $2 \mathrm{~h}$ immersion, identify the two bottom features as being Al-Mn intermetallics and the two top particles containing a high concentration of $\mathrm{O}$, which could be attributed to corrosion product. ${ }^{35}$

To confirm that the variations in current in the SECM map (Figure 5A) are related to an intrinsic change in surface reactivity, localized probe approach curves were performed over the different microstructure features, the $\alpha$-phase ([3]), $\beta$-phase ([2]) and intermetallic ([1]), Figure 5B. Consistent with the results presented in Figure 3, an intermediate behavior is observed when performing a probe approach curve over each of these locations on the $\mathrm{Mg}$ alloy, Figure 5B. At normalized distance $(\mathrm{L})<1$, higher normalized currents for the Al-Mn intermetallic are measured in comparison to the $\beta$-phase and $\alpha$-phase. These results are not following the same trend as what was previously observed in ethylene glycol. ${ }^{23}$ In the case of non-aqueous media, the $\alpha$-phase presented the highest feedback current. ${ }^{23}$ Herein, we measure the highest feedback current over $\beta$-phase and Al-Mn intermetallics, and thus the electrolyte affects the $\mathrm{FcMeOH}-\mathrm{Mg}$ alloy interaction. This drastic change in behavior raised concerns about the ability of $\mathrm{FcMeOH}$ to properly record and extract localized surface reactivity in aqueous media, while an evident variation in reactivity is observed, Figure 5B. 


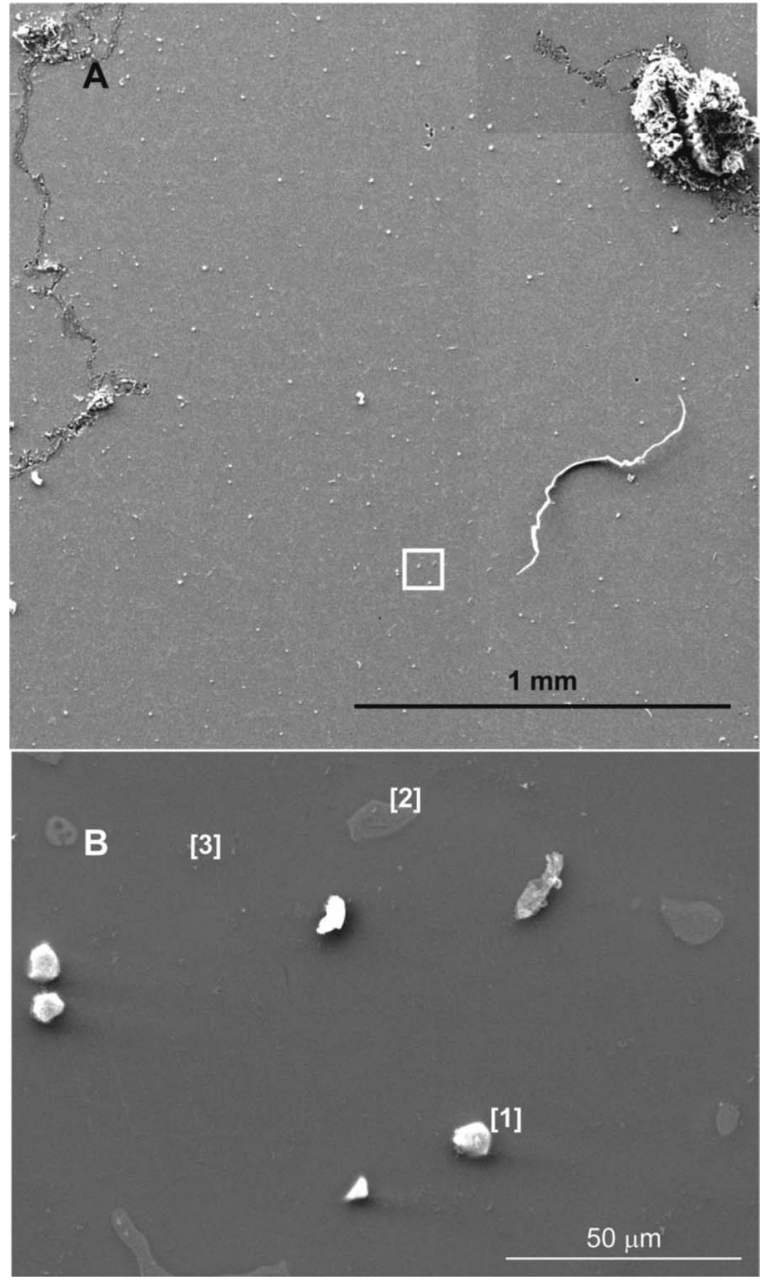

Figure 4. A) $2 \times 2 \mathrm{~mm}$ area electron micrograph of a corroded sand cast AM50 $\mathrm{Mg}$ alloy for $2 \mathrm{~h}$ in a $1 \mathrm{mM} \mathrm{FcMeOH}$ and $0.016 \mathrm{wt} . \% \mathrm{NaCl}$ solution.; B) Higher magnification electron micrograph of the area of interest (white square in A). Number labels represent locations where probe approach curves are performed (Figure 5).

Influences on the FcMeOH feedback current.- The contrast observed in the feedback current maps may be affected by:

1. Changes in surface topography;

2. Phase polarization and intrinsic exchange current rates, and

3. Presence of a heterogeneous porous corrosion product film forming on the $\mathrm{Mg}$ alloy, which hinders further corrosion.

The topographic effect has been evaluated by measuring topography changes under the same experimental conditions with the shear force module of a SECM using an empty microcapillary as probe. ${ }^{36}$ The obtained topographic features $(<300 \mathrm{~nm})$ lead to FcMeOH SECM feedback current changes that are lower than those observed in Figure $5 \mathrm{~A} .{ }^{34}$ Furthermore, these changes in topography would not account for different measured apparent rate constants by approach curves. Thus, point 1 can be excluded as a significant contributor to the observed current heterogeneities.

In considering the effect of phase polarization and intrinsic kinetics of the pure metal phases with respect to $\mathrm{FcMeOH}$ regeneration, it is important to note that the standard potential of the $\mathrm{FcMeOH} / \mathrm{FcMeOH}^{+}$ couple $\left(+0.150 \mathrm{~V}\right.$ vs. $\left.\mathrm{Ag} / \mathrm{AgCl}^{37}\right)$ is significantly higher than the corrosion potential of the most cathodic microstructures in magnesium, observed around $-1.3 \mathrm{~V}$ to $-1.4 \mathrm{~V}$ vs. $\mathrm{Ag} / \mathrm{AgCl} .^{20,38} \mathrm{On}$ a clean metal surface, the very high overpotential of $\sim 1.5 \mathrm{~V}$ towards the reduction
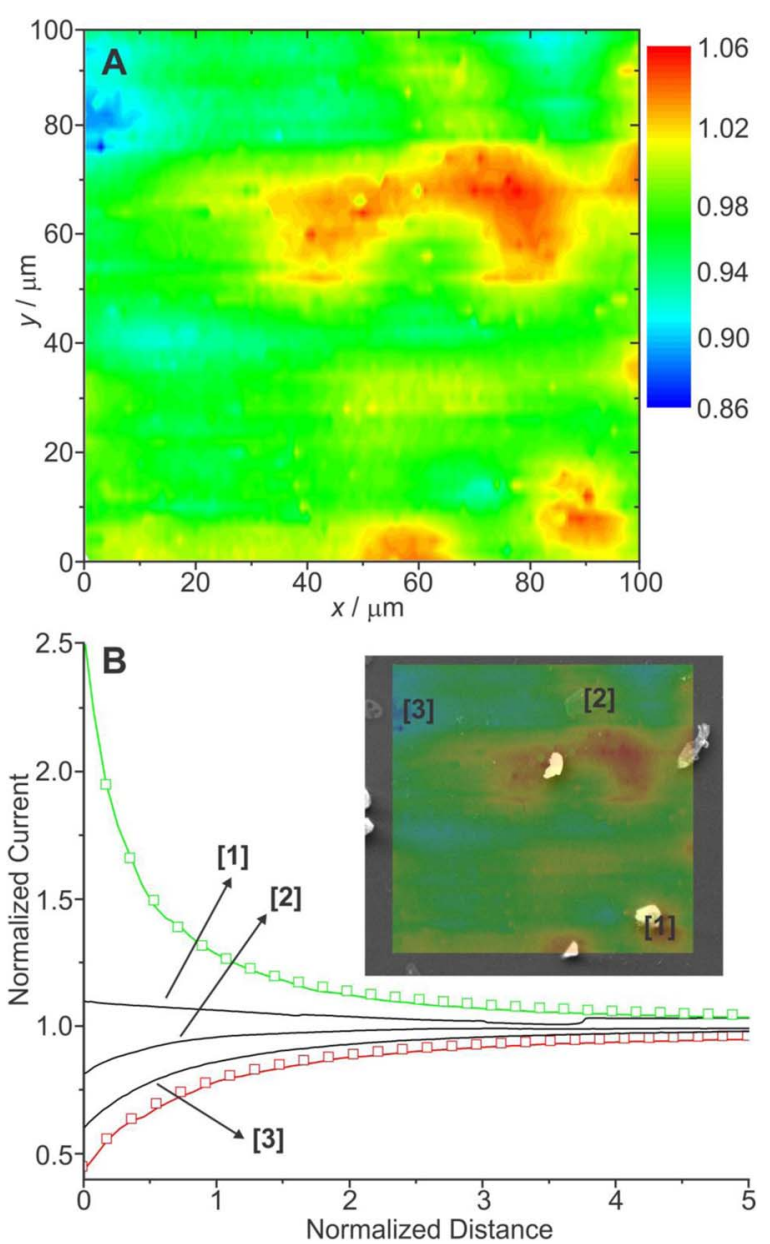

Figure 5. A) Normalized currents SECM map of the $100 \times 100 \mu \mathrm{m}$ area of interest (Figure 4B) recorded at $5 \mu \mathrm{m} / \mathrm{s}$ using a C-ME with a tip-to-substrate distance of $5 \mu \mathrm{m}$ while polarizing the tip at $+350 \mathrm{mV}$ vs. $\mathrm{Ag} \mid \mathrm{AgCl}$ following a 15 min immersion.; B) Probe approach curves recorded over specific locations (see inset) while polarizing the tip at $+350 \mathrm{mV}$ vs. $\mathrm{Ag} \mid \mathrm{AgCl}$. Pure positive (green curve) and negative (red curve) feedback probe approach curves are presented for comparison.

of $\mathrm{FcMeOH}^{+}$would lead to a diffusion limited pure positive feedback behavior.

The observed intermediate rate constants are thus only conceivable when considering the formation of a corrosion product film. ${ }^{39}$ In this case, the growth of an inert porous layer hinders the diffusion of $\mathrm{FcMeOH}^{+} / \mathrm{FcMeOH}$ significantly enough to reduce the observed rate constant to a fraction of the one expected from the pure material.

Evaluation of the corrosion product film by electron microscopy.To verify whether a significant change in the corrosion product thickness occurred, three sand cast AM50 Mg alloys corroded for $15 \mathrm{~min}$, $1 \mathrm{~h}$ and $4 \mathrm{~h}$ in $0.016 \mathrm{wt} . \% \mathrm{NaCl}$ were analyzed by SEM. For the purpose of analyzing the corrosion product film thickness, a tungsten film was deposited onto the sample, after which three $\sim 7 \times 7 \mu \mathrm{m}$ trenches per sample were milled with a focused ion beam, Figure 6A. The corrosion product film thickness was subsequently measured in the electron microscope, Figure 6B. Average corrosion product film thicknesses of $37 \pm 3 \mathrm{~nm}, 71 \pm 16 \mathrm{~nm}$ and $186 \pm 75 \mathrm{~nm}$ (intervals are standard deviations) for the samples corroded for $15 \mathrm{~min}, 1 \mathrm{~h}$ and $4 \mathrm{~h}$, respectively, were measured. This analysis was further supplemented by performing a FIB lift out of one trench to assess the overall corrosion product film porosity.

A TEM lamella of a region encompassing the three microstructures was extracted from the sample corroded during a $4 \mathrm{~h}$ immersion to characterize its corrosion product film porosity, Figure 7A (location 

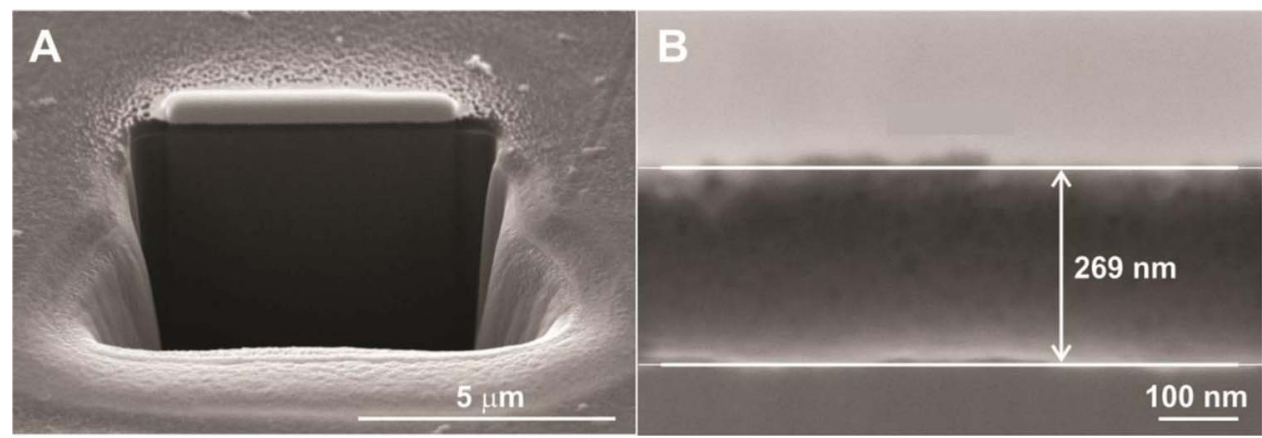

Figure 6. A) $7 \times 7 \mu \mathrm{m}$ trench milled using FIB over a sand cast AM50 Mg alloy sample corroded for $4 \mathrm{~h}$ in 0.016 wt. $\% \mathrm{NaCl}$ aqueous solution; B) Corrosion product film thickness extracted following milling.

on the sample is presented in Figure S4). The brightest region within the $\mathrm{Mg}$ layer, was representative of an $\mathrm{Al}_{8} \mathrm{Mn}_{5}$ intermetallic while an Al-rich region, also brighter than the $\alpha$-Mg matrix, is also observed and representative of the $\beta$-phase $\left(\mathrm{Mg}_{17} \mathrm{Al}_{12}\right)$. The TEM micrograph reveals further that the corrosion product film is highly porous over the intermetallic (Figure 7Ai) in comparison to the film present over the $\alpha$ and $\beta$-phases (Figure 7Aiii and Figure 7Aii).

To quantify the general porosity of the corrosion product film, EELS characterization of a selected region (white square in Figure 7A) over an $\alpha$-phase was performed. This analysis allows quantification of $\mathrm{Mg}$ and $\mathrm{W}$, the latter filling the voids of the film. Using the EELS $\mathrm{W}$ signal over the $\mathrm{W}$ film and inside the $\mathrm{Mg}$ alloy as references for $100 \%$ and $0 \% \mathrm{~W}$ respectively, it is possible to obtain an overall porosity of $\sim 0.6$, Figure $7 B$. Similarly, a thresholded top view SEM image yielded an estimated porosity of $\sim 0.6$. Importantly, the corrosion product film presents columnar features, which are more porous when moving towards the solution-corrosion product film interface and denser at the $\mathrm{Mg}$ alloy-corrosion product film interface. To describe this change in porosity as moving from the $\mathrm{W}$ layer towards the $\mathrm{Mg}$ alloy, integrated EELS line scans across the layer were extracted with respect to their elemental composition, Figure 7C. A linear decrease in the $\mathrm{W}$ content across the corrosion product film is observed as the content in $\mathrm{Mg}$ increases accordingly. Interestingly, an enrichment in $\mathrm{Al}$ is also observed within the corrosion product film highlighting a preferential dissolution of $\mathrm{Mg}$ leaving the nobler metal behind $(40<$ pixels $<55)$.
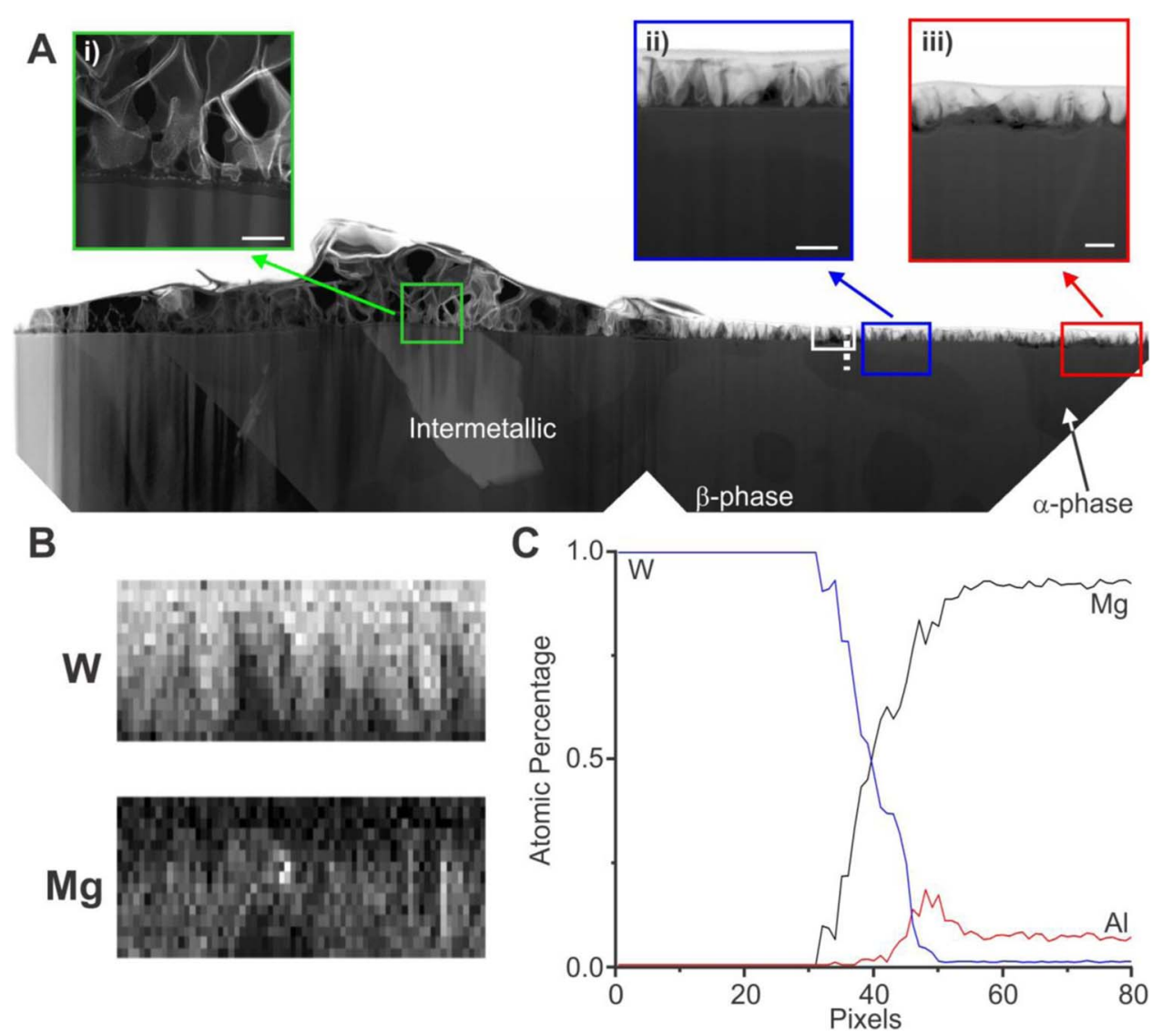

Figure 7. A) TEM lamella lifted from a sand cast AM50 Mg alloy following a $4 \mathrm{~h}$ immersion in a $0.016 \mathrm{wt} . \% \mathrm{NaCl}$ electrolyte solution (see location in Figure S4). i)-ii)-iii) are higher magnification micrographs of the corrosion product film observed over the various microstructures, namely over the intermetallic, $\beta$-phase and $\alpha$-phase, respectively. The scale bars represent $100 \mathrm{~nm}$; B) EELS maps of the W and Mg signals of the location highlighted in white in A); C) Line scan of the EELS signals recorded across the white dashed line in $\mathrm{A}$ ) for $\mathrm{Mg}, \mathrm{Al}$ and $\mathrm{W}$. 
Numerical model for the extraction of the corrosion product thickness and porosity.- From the TEM and SEM analysis presented in Figures 6 and 7, it is evident that the corrosion product film thickness and porosity is changing as immersion time varies. Moreover, the presence of such porous films at the surface was shown to affect the apparent heterogeneous rate constant extracted from the probe approach curves. With the objective of correlating the apparent heterogeneous rate constants to the film thickness and porosity, a numerical model in COMSOL Multiphysics(C) was established. In this model, the $\mathrm{Mg}$ surface is regarded as a homogenously fast reacting surface, as discussed above, with a diffusion hindering porous layer representing the corrosion product. Moreover, a one-dimensional diffusion model was employed as the electron transfer rates are assumed to be the same over the entire $\mathrm{Mg}$ alloy heterogeneous surface, due to the overpotential between the corroding surface and redox mediator as mentioned above. Apparent heterogeneous rate constants were extracted from probe approach curves over $\alpha$-phase, a microstructure feature that is larger than the microelectrode size and the heterogeneities in the corrosion product film more homogeneous. A complete description of the model can be found in supporting information. It confirms the experimental observation that approach curves over the porous film behave similar to heterogeneous reaction rate theory, ${ }^{40,41}$ and can be fitted with established analytical approximations. The extracted apparent heterogeneous reaction rates are correlated to film porosity, tortuosity and thickness. This relationship is described in Eq. 4 (see supporting information for full derivation details) for a stationary one-dimensional diffusion system:

$$
k^{a}=\frac{D p}{\tau d+\frac{D p}{k^{s}}}
$$

where $k^{a}$ is the apparent heterogeneous rate constant $\left(\mathrm{cm} \mathrm{s}^{-1}\right), D$ is the diffusion coefficient $\left(\mathrm{cm}^{2} \mathrm{~s}^{-1}\right), p$ is the unitless porosity parameter, $\tau$ is the unitless tortuosity factor representing the path necessary for a molecule to reach the surface, $d$ is the corrosion product film thickness $(\mathrm{cm})$, and $k^{s}$ is the underlying substrate rate constant $(\mathrm{cm}$ $\mathrm{s}^{-1}$ ). Numerical simulations show that the equation is not only applicable for SECM approach curves over columnar films, which restrict diffusion to the dimension perpendicular to the surface, but also for isotropically porous surface films in cases with high substrate rate constants $\left(>0.1 \mathrm{~cm} \mathrm{~s}^{-1}\right)$.

Eq. 4 determines film properties accurately for films exhibiting columnar pores $(\tau=1)$, as TEM imaging is suggesting in this case (Figure 7A). When applying Eq. 4, we also considered that the corrosion product porosity above the $\alpha$-phase is inhomogeneous, as shown by SEM imaging and in literature. ${ }^{42}$ In view of EELS measurements of tungsten filled pores (Figures 7B and 7C), it appears that the porosity changes linearly from a highly dense film at the metal surface to a highly porous film at the electrolyte interface. These considerations have been applied to Eq. 4, solving for 50 thin layer iterations of the film and using the apparent rate constant of the underlying film as substrate rate constant for the overlying film. At the metal interface, it was assumed that the substrate rate constant is fast, reducing Eq. 4 to

$$
k^{a}=\frac{D p}{\tau d}
$$

Using this method, the decrease in apparent rate constant observed in Figure 3 is consistent with a persisting linear porosity profile during film growth, i.e. both dense and porous fractions of the film grow simultaneously. By taking the FIB-SEM film thickness measurement at 15 minutes $(37 \mathrm{~nm})$ as a reference to obtain the porosity profile, varying linearly in porosity from $3.7 \times 10^{-5}$ to 0.9 , it is possible to determine the film thicknesses for longer immersions from the apparent rate constants. Figure 8 shows that the extracted film thicknesses by FIB-SEM correspond well to the measured thicknesses within the experimental errors (grey boxes).

While it is not possible to extend such quantitative analysis to the recorded current map (Figure 5A) due to the relative microstructure size with respect to the size of the microelectrode ${ }^{43}$, which results in

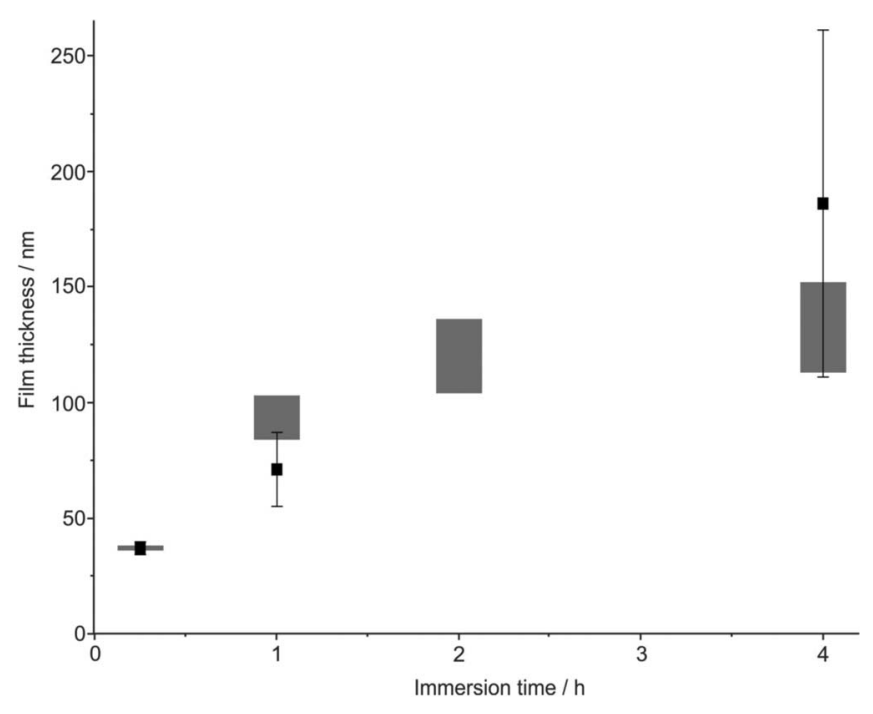

Figure 8. Comparison between film thicknesses from FIB-SEM measurements (black squares, error bars represent standard deviation of triplicates, no measurement was performed for a $2 \mathrm{~h}$ immersed sample), and from SECM approach curve apparent rate constants (see Figure 3) using Eq. 4 (grey boxes, assuming a statistical error of $\pm 0.1 \times 10^{-3} \mathrm{~cm} \mathrm{~s}^{-1}$ on the apparent rate constants).

a convoluted signal from the different microstructures, increasing the error, it is reasonable to compare qualitatively the overall blocking ability of the corrosion product layer across the map. As such, high current regions over the intermetallic particles are due to the significantly more porous nature of the film in these regions (Figure 7A), whereas low current regions over the $\alpha$-phase reflect a lower film porosity near the metal - corrosion product film interface.

Normally, the corrosion product thickness and porosity are determined using a FIB, TEM and SEM analysis, as presented in Figure 7. Such analysis is time consuming and costly, but also has to be performed ex situ, bringing into question whether the obtained results have been altered by subsequent sample handling. In situ SECM approach curve measurements, however, are performed during the corrosion measurement, and thus do not require significant additional time or costs. Eq. 4 provides an estimate of the dependence of the measured apparent rate constant on film parameters, including thickness and porosity, based on a one-dimensional system. Numerical simulations to extract film parameters from apparent rate constants can be used. Notably, this methodology is not only valid for corrosion product measurements, but can be applied to probe any porous layer of insulating material on an electrode.

\section{Conclusions}

The corrosion of magnesium alloys was monitored with the feedback mode of SECM using C-MEs. In doing so, the advantage of $\mathrm{C}$-MEs to selectively probe the redox mediator regeneration without $\mathrm{H}_{2}$ current contribution was shown. Regeneration rates of $\mathrm{FcMeOH}$ at the various microstructures of magnesium alloys are not dependent on the clean metal's intrinsic reactivity or relative polarization. Thus, to quantify the intrinsic regeneration rates of the redox mediator over clean microstructures during microgalvanic corrosion, a redox mediator possessing a reduction potential closer to the corrosion potential of magnesium alloys should be envisioned. For $\mathrm{FcMeOH}$, the time and microstructure dependent regeneration rates have instead been linked to inhomogeneous corrosion product build-up. A relationship between the apparent heterogeneous rate constants and the film parameters, porosity, tortuosity and thickness. With these models it is possible to determine the general porosity and thickness of insulating porous layers deposited on an electrode from SECM probe approach curves. Further, the apparent rate constant measurements not only 
provide an estimate of the 3D corrosion product structure, but in particular provide a direct in situ measure of the highly relevant local passivation by corrosion product build-up.

\section{Acknowledgments}

The authors acknowledge funding by General Motors Canada and the Natural Sciences and Engineering Research Council of Canada (NSERC, 140577928).

\section{References}

1. M. V. Mirkin, W. Nogala, J. Velmurugan, and Y. Wang, Physical Chemistry Chemical Physics, 13, 21196 (2011).

2. G. Wittstock, M. Burchardt, S. E. Pust, Y. Shen, and C. Zhao, Angewandte Chemie (International Edition), 46, 1584 (2007).

3. T. E. Lister and P. J. Pinhero, Electrochemical and Solid-State Letters, 5, B33 (2002).

4. K. Fushimi and M. Seo, Journal of The Electrochemical Society, 148, B450 (2001).

5. P. Dauphin-Ducharme, R. M. Asmussen, D. W. Shoesmith, and J. Mauzeroll, Journal of Electroanalytical Chemistry, 736, 61 (2015).

6. J. Izquierdo, A. Kiss, J. J. Santana, L. Nagy, I. Bitter, H. S. Isaacs, G. Nagy, and R. M. Souto, Journal of The Electrochemical Society, 160, C451 (2013).

7. S. V. Lamaka, O. V. Karavai, A. C. Bastos, M. L. Zheludkevich, and M. G. S. Ferreira, Electrochemistry Communications, 10, 259 (2008).

8. C. Nowierski, J. J. Noël, D. W. Shoesmith, and Z. Ding, Electrochemistry Communications, 11, 1234 (2009).

9. S. S. Jamali, S. E. Moulton, D. E. Tallman, M. Forsyth, J. Weber, and G. G. Wallace, Corrosion Science, 86, 93 (2014).

10. W. Liu, F. Cao, Y. Xia, L. Chang, and J. Zhang, Electrochimica Acta, 132, 377 (2014)

11. X. Liu, T. Zhang, Y. Shao, G. Meng, and F. Wang, Corrosion Science, 51, 1772 (2009).

12. X. Liu, T. Zhang, Y. Shao, G. Meng, and F. Wang, Materials and Corrosion, 63, 505 (2012)

13. H. He, Z. Qin, and D. W. Shoesmith, Electrochimica Acta, 56, 53 (2010).

14. R. Zhu, Z. Qin, J. J. Noël, D. W. Shoesmith, and Z. Ding, Analytical Chemistry, 80, 1437 (2008)

15. S. S. Jamali, S. E. Moulton, D. E. Tallman, M. Forsyth, J. Weber, and G. G. Wallace, Electrochimica Acta, 152, 294 (2015).

16. U. M. Tefashe, M. E. Snowden, P. Dauphin-Ducharme, M. Danaie, G. A. Botton, and J. Mauzeroll, Journal of Electroanalytical Chemistry, 720-721, 121 (2014).

17. P. Dauphin-Ducharme, R. Matthew Asmussen, U. M. Tefashe, M. Danaie, W. Jeffrey Binns, P. Jakupi, G. A. Botton, D. W. Shoesmith, and J. Mauzeroll, Journal of The Electrochemical Society, 161, C557 (2014).
18. G. S. Frankel, A. Samaniego, and N. Birbilis, Corrosion Science, 70, 104 (2013).

19. D. R. Lide, CRC Handbook of Chemistry and Physics, 94th Edition, Taylor \& Francis, 2013.

20. T. Cain, L. G. Bland, N. Birbilis, and J. R. Scully, Corrosion, 70, 1043 (2014).

21. N. Birbilis, R. Souto, and S. Thomas, Corrosion, 71, 171 (2015).

22. W. Miao, Z. Ding, and A. J. Bard, The Journal of Physical Chemistry B, 106, 1392 (2002).

23. R. Matthew Asmussen, W. Jeffrey Binns, P. Jakupi, P. Dauphin-Ducharme, U. M. Tefashe, J. Mauzeroll, and D. Shoesmith, Corrosion Science, 93, 70 (2015).

24. N. Birbilis, G. Williams, K. Gusieva, A. Samaniego, M. A. Gibson, and H. N. McMurray, Electrochemistry Communications, 34, 295 (2013).

25. C. H. Paik, H. S. White, and R. C. Alkire, Journal of The Electrochemical Society, 147, 4120 (2000).

26. I. Serebrennikova, S. Lee, and H. S. White, Faraday Discussions, 121, 199 (2002)

27. S. B. Basame and H. S. White, Analytical Chemistry, 71, 3166 (1999).

28. J. Hirsch and T. Al-Samman, Acta Materialia, 61, 818 (2013).

29. D. Trinh, P. Dauphin Ducharme, U. Mengesha Tefashe, J. R. Kish, and J. Mauzeroll, Analytical Chemistry, 84, 9899 (2012).

30. L. Danis, D. Polcari, A. Kwan, S. M. Gateman, and J. Mauzeroll, Analytical Chemistry, 87, 2565 (2015).

31. T. J. Smith and K. J. Stevenson, 4 - Reference Electrodes, in: C. G. Zoski (Ed.) Handbook of Electrochemistry, Elsevier, Amsterdam, 2007, pp. 73-100.

32. M. Danaie, R. M. Asmussen, P. Jakupi, D. W. Shoesmith, and G. A. Botton, Corrosion Science, 77, 151 (2013).

33. B. L'vov and A. Galwey, Journal of Thermal Analysis and Calorimetry, 112, 815 (2013).

34. R. Cornut, S. Griveau, and C. Lefrou, Journal of Electroanalytical Chemistry, 650 55 (2010).

35. R. M. Asmussen, P. Jakupi, M. Danaie, G. A. Botton, and D. W. Shoesmith, Corrosion Science, 75, 114 (2013).

36. P. Dauphin-Ducharme, W. J. Binns, M. E. Snowden, D. W. Shoesmith, and J. Mauzeroll, Faraday Discussions, 180, 331 (2015).

37. M. A. Mezour, M. Morin, and J. Mauzeroll, Analytical Chemistry, 83, 2378 (2011).

38. M. F. Hurley, C. M. Efaw, P. H. Davis, J. R. Croteau, E. Graugnard, and N. Birbilis Corrosion, 71, 160 (2014).

39. G. O. Ilevbare and J. R. Scully, Corrosion (USA), 57, 134 (2001).

40. K. Mansikkamäki, C. Johans, and K. Kontturi, Journal of The Electrochemical Society, 153, B22 (2006)

41. K. Mansikkamäki, P. Ahonen, G. Fabricius, L. Murtomäki, and K. Kontturi, Journal of The Electrochemical Society, 152, B12 (2005).

42. M. Taheri, M. Danaie, and J. R. Kish, Journal of The Electrochemical Society, 161, C89 (2014)

43. Q. Zhou, Y. Wang, D. Tallman, and M. B. Jensen, Journal of The Electrochemical Society, 159, H644 (2012) 